\section{Comparison of 'Marion' to Thornless Blackberry Genotypes as Individually Quick-frozen and Puree Products}

\author{
B.M. Yorgey \\ Department of Food Science, Oregon State University, Corvallis, OR 97331
}

C.E. Finn

United States Department of Agriculture, Agricultural Research Service, HCRL, Corvallis, OR 97330

Additional index words. trailing blackberry, fruit processing, IQF

\begin{abstract}
The trailing blackberries (Rubus sp. L.), particularly 'Marion', are the primary blackberries grown for the processing market and they are largely machine harvested. While 'Marion' is well known for its processed fruit quality, particularly flavor, aroma, and perception of low seediness, it has spines (thorns) that can be dislodged when machine harvested and end up in the product. A primary goal of the USDA-ARS blackberry breeding program in Corvallis is the development of cultivars that are comparable to 'Marion' in fruit quality but are spineless (thornless). Nine thornless selections were compared with four standard cultivars as individually quick-frozen (IQF) and puree products in a blind evaluation. Each sample was scored panelists from the blackberry industry and research program. IQF samples were scored for appearance, color, seediness, flavor, and overall quality by 21 panelists and purees were scored for color, flavor, aroma, and overall quality by 25 panelists. Both panels used a 9 point hedonic scale $(1=$ dislike extremely, $5=$ neither like nor dislike, $9=$ like extremely). With the exception of color, there were significant differences among all genotypes for all traits evaluated in the IQF and pureed products. ORUS 1380-1 was ranked similar to 'Marion' and significantly better than 'Waldo', in overall quality of the IQF product. In puree form, ORUS 1843-1 and ORUS 1843-3 had the highest ranking in overall quality, but were only both statistically different from ORUS 1489-2. For pureed product flavor, ORUS 1843-1 was the highest rated selection but was not statistically different from 'Marion'. While ORUS 1843-1 and ORUS 1843-3 hold great promise, they are from a cross between wild collected Rubus ursinus Cham. \& Schlt. and 'Waldo' and as a result have some negative characteristics of the native species, particularly small fruit size. The puree quality of NZ 9128R-1, NZ 9351-4 and ORUS 1380-1 was similar to 'Marion' and these genotypes offer promise as thornless replacements for 'Marion'.
\end{abstract}

Oregon is the world's leading blackberry (Rubus sp. L.) producer with 16 to $20 \times 10^{6}$ $\mathrm{kg}$ produced annually (Oregon Agricultural Statistical Service, 2002). Over $95 \%$ of the harvest is processed, most commonly frozen as an individually quick frozen (IQF) or pureed product. From these primary processed products, innumerable products for consumers are produced.

While some fruit designated for IQF processing is hand-picked, the bulk of the production is machine harvested. Machine harvesting is much more economically viable than hand harvesting and produces a more uniformly mature pick than does hand harvesting. Unfortunately, machine harvesting can also lead to much greater spine (thorn) contamination of the picked product (Strik and Buller, 2002). While entire petioles with spines can be removed on picking lines, this is impossible for spines that have broken off in the fruit. This can lead to expensive rejection of shipped fruit or potential lawsuits from consumers who feel they are harmed by the spines. As a result, spineless (thornless) cultivars have been a

\footnotetext{
Received for publication 3 Feb. 2004. Accepted for publication 11 Dec. 2004. We would like to acknowledge the generous support of the Oregon Raspberry and Blackberry Commission. We would like to thank our panelists for the time and effort devoted to this evaluation.
}

top priority for the industry and the USDA-ARS breeding program in Corvallis, Ore.

Breeding programs worldwidehave relied on several sources of thornlessness in their quest to develop thornless cultivars (Hall, 1990). In the eastern U.S., the primary source of thornlessness has been from 'Merton Thornless'. 'Merton Thornless' is a tetraploid and the gene for thornlessness is recessive. Use of 'Merton Thornless' has led to the thornless eastern semi-erect (i.e., 'Black Satin', 'Chester Thornless', 'Triple Crown') and erect (i.e., 'Arapaho', 'Navaho', 'Apache') cultivars. In Oregon, New Zealand, Australia, and the United Kingdom, the primary source of thornlessness has been from 'Austin Thornless'. This dominant gene is in a hexaploid background making it more readily useful in breeding in the trailing germplasm. This gene is in the background of the thornless trailing blackberries including 'Waldo', 'Adrienne', 'Douglass', and 'Murrindindi'. More recently, Hall etal. (1986) developed the 'Lincoln Logan' source of thornlessness. The 'Lincoln Logan' source of thornlessness is useful in breeding the higher ploidy trailing blackberries, is dominant and, because thornless genotypes can be identified in very young genotypes before they are put in the field, can make seedling evaluation and progress more efficient. The 'Lincoln Logan' source of thornlessness is found in some advanced selections and the recently released 'Waimate' (H. Hall, personal communication). While the fruit processing characteristics of cultivars derived from 'Merton Thornless' and 'Austin Thornless' are known, they are not for selections derived from 'Lincoln Logan'.

'Marion' is the predominant blackberry cultivar grown for processing in Oregon and is felt by the industry to have ideal processing characteristics including high soluble solids, high titratable acidity, excellent flavor, low perception of seediness (pyrenes), good color, and good size (Finn et al., 1997). Unfortunately, 'Marion' is thorny. Therefore, the primary objective of the USDA-ARS breeding program is to develop a thornless cultivar with 'Marion' processing characteristics. While thornless selections were unusual in the late 1980s in the USDA-ARS breeding program, they are now numerous. We have identified selections that are superior to 'Marion' in nearly all horticultural characteristics. However, it has been difficult to confidently identify those that will produce as high a quality processed product as 'Marion'.

Compositional characteristics have been compared among trailing cultivars and selections but this has not yet been tied to organoleptic evaluation(Fan-Chiang, 1999; Klesk and Qian, 2003). Preference and acceptability of a processed fruit product can only be demonstrated by evaluating with a human panel.

The objective of this research was to use a blind panel consisting of blackberry industry members and scientists involved with the breeding program to compare the performance of a group of cultivars and thornless advanced selections as IQF and pureed products.

\section{Materials and Methods}

The genotypes selected for evaluation included standard industry cultivars and a number of advanced selections in the USDA-ARS breeding program(Table 1). All of the genotypes were spineless with the exception of 'Marion' and 'Silvan'. The selections were chosen because they are among the most promising in the breeding program and have already proven themselves to have good horticultural characteristics, yield, and/or have performed well in previous preliminary blind evaluations. Two of the selections (ORUS 1843-1, ORUS 1843-3) are from a cross between $R$. ursinus Cham. \& Schlt. and 'Waldo', a thornless cultivar. The USDA-ARS program had collected this species from throughout the Pacific Northwest region of North America, evaluated populations in a common garden in Corvallis, Ore., made selections within these populations, and used them in crosses (Finn, 2001). 'Marion' has many characteristics that can trace to its $R$. ursinus heritage including fruit flavor and aroma, and the lack of perceived seediness of the fruit(Finn et al., 1997). These selections combine the plant habit and fresh fruit quality of the species parent with the disease resistance and thornlessness of the cultivated parent. We were interested in how these selections compared for processed fruit quality. Several of the advanced selections tested in this evaluation are in the process of being released as cultivars. 
Table 1. Background information for 13 blackberry genotypes evaluated by a blind panel as IQF and/or pureed fruit samples.

\begin{tabular}{|c|c|c|c|c|}
\hline \multirow{2}{*}{$\begin{array}{l}\text { Selection } \\
\text { or cultivar }\end{array}$} & \multicolumn{2}{|c|}{$\begin{array}{c}\text { Samples } \\
\text { evaluated }\end{array}$} & \multirow[b]{2}{*}{ Genotype ancestry } & \multirow[b]{2}{*}{ Comments $^{\mathrm{z}}$} \\
\hline & $\overline{\mathrm{IQF}}$ & Puree & & \\
\hline Chester Thornless & $\mathrm{N}$ & $\mathrm{Y}$ & SIUS $47 \times$ Thornfree & Standard semi-erect; selected in Illinois; MT \\
\hline Marion & $\mathrm{Y}$ & $\mathrm{Y}$ & Chehalem $\times$ Olallie & Industry standard; thorny \\
\hline Silvan & $\mathrm{Y}$ & $\mathrm{Y}$ & OSC $742 \times$ Marion & Industry standard; thorny; complement/replacement for 'Marion'? \\
\hline Waldo & $\mathrm{Y}$ & Y & OSC $1122 \times$ OSC 1367 & Standard thornless trailing cultivar \\
\hline NZ 9351-4 & $\mathrm{Y}$ & Y & NZ 8754RH-1 × NZ 8928RCE.6 & New Zealand cross; selected in Oregon; LL \\
\hline NZ 9337-1 & $\mathrm{Y}$ & $\mathrm{Y}$ & NZ 8629014.10 × NZ 8928RCF.7 & New Zealand cross; selected in Oregon; LL \\
\hline NZ 9128R-1 & $\mathrm{Y}$ & $\mathrm{Y}$ & Kotata $\times$ NZ 8610 L-163 & New Zealand cross; selected in Oregon; AT \\
\hline ORUS $1843-3$ & $\mathrm{Y}$ & $\mathrm{Y}$ & GP 9-24 × Waldo & Rubus ursinus selection $\times$ thornless standard; AT \\
\hline ORUS 1843-1 & $\mathrm{Y}$ & $\mathrm{Y}$ & GP 9-24 × Waldo & Rubus ursinus selection $\times$ thornless standard; AT \\
\hline ORUS $1380-1$ & $\mathrm{Y}$ & $\mathrm{Y}$ & ORUS $1117-11 \times$ ORUS $1122-1$ & Selection from two USDA selections; AT \\
\hline ORUS 1489-1 & $\mathrm{Y}$ & $\mathrm{N}$ & N-71 $\times$ ORUS $828-27$ & Selection from cross among New Zealand and USDA selection; AT \\
\hline ORUS $1486-2$ & $\mathrm{Y}$ & $\mathrm{Y}$ & Marion $\times$ Waldo & Selection from two USDA selections; AT \\
\hline ORUS $1489-2$ & $\mathrm{Y}$ & $\mathrm{Y}$ & $\mathrm{N}-71 \times$ ORUS $828-27$ & Selection from cross among New Zealand and USDA selection; AT \\
\hline
\end{tabular}

'Source of genetic spinelessness: AT = 'Austin Thornless'; LL = 'Lincoln Logan'; MT = 'Merton Thornless'; All New Zealand crosses were made by H. Hall, New Zealand HortResearch Inc., Motueka, New Zealand; All ORUS selections were derived from crossed made by the USDA-ARS in Oregon.

Randomized complete blocks containing many selections and cultivars were established at the Oregon State University North Willamette Research and Extension Center, Aurora, Ore., in 1999 and 2000 as part of the ongoing USDA-ARS-OSU breeding program. Fruit was hand harvested once a week to determine yield and fruit weight in Summer 2001. After weighing, the fruit was put immediately into a walk-in cooler set to $1{ }^{\circ} \mathrm{C}$. Later the same day, the fruit was transported to Oregon State University's Department of Food Science \& Technology, Corvallis, and stored at $1^{\circ} \mathrm{C}$ until processing. Processing was carried out in the Oregon State University Department of Food Science and Technology Pilot Plant which has been designed to mimic commercial processing facilities. Within $24 \mathrm{~h}$ of harvest, the fruit were removed from the cooler in small batches, washed, sorted, and arranged on stainless steel screens for freezing in a blast freezer at $-35^{\circ} \mathrm{C}$. Once frozen, the fruit were packed into $15-\mathrm{L}$ buckets and transferred to $\mathrm{a}-10{ }^{\circ} \mathrm{C}$ freezer for storage.

For the IQF evaluation, frozen berries were thawed overnight at $1^{\circ} \mathrm{C}$. Each genotype was given a random three digit identifier code. One hour before the evaluation, four to five berries of each genotype were placed in 5-oz coded clear plastic cups and allowed to warm to room temperature. Sample cups were placed on serving trays in random order for presentation to evaluators. IQF samples were rated for color, appearance, flavor, seediness, and overall quality using a 9-point hedonic scale $(1=$ dislike extremely, $5=$ neither like nor dislike, $9=$ like extremely).

For the puree evaluation, frozen berries were thawed and processed through a pilot scale pulping/finishing machine using $0.06858-\mathrm{cm}$ screens. Puree was stored overnight at $1{ }^{\circ} \mathrm{C}$. Each selection or cultivar was given a random three digit identifier code different from those used for the IQF evaluation. One hour before the evaluation, about 2 oz of each genotype were poured into coded clear plastic cups and allowed to warm to room temperature. Sample cups were placed on serving trays in random order for presentation to evaluators. Puree samples were rated for aroma, flavor, color, and overall quality using the same 9 point hedonic scale.

The untrained, expert panel consisted of in- dustry and research representatives all of whom work with blackberries. The industry members included quality control personnel, fieldmen, growers, plant production supervisors, and sales people. The research members included those working in the breeding program in the field and in the lab and Food Science professors and graduate students working on blackberry anthocyanins and flavor compounds as well as those working on processing and evaluation directly linked to the breeding program.

Evaluation scores were analyzed using twowayANOVA(with no replication) to determine mean hedonic scores and errors. These data were then used to calculate Tukey's honestly significant difference. These data are displayed in Fig. 1 for IQF samples and Fig. 2 for puree samples.

\section{Results and discussion}

$I Q F$ evaluation. There were significant differences among the genotypes for all traits except color (Fig. 1). Though not statistically different from any other sample, 'Marion' scored near the bottom of the group for color along with 'Silvan'. ORUS 1380-1 was the top ranked genotype for appearance. The two lowest ranked selections, ORUS 1843-1 and ORUS 1843-3, were largely ranked low in appearance due to their small berry size. Their fruit size is smaller than any of the other selections tested since one of the parents of each of these selections are from wild populations of $R$. ursinus. Flavor was ranked highest in 'Marion', followed by ORUS 1380-1, ORUS 1843-1, NZ 9337-1, ORUS 1489-1, and NZ 9351-4. ORUS 1843-3 did not score as well as its sibling ORUS 1843-1 for flavor in part because a few of its samples were scored very low by some evaluators due to the perception of Botrytis cinerea Fr. :Pers. contamination. Seediness is affected by the evaluators' perception as they chew the pyrenes (seeds) in the fruit which vary in size and shape. 'Marion' is perceived to be less seedy than many other cultivars while 'Thornless Evergreen' is perceived as very seedy. While not significantly different, ORUS 1843-1 and ORUS 1489-2 were rated better than 'Marion' in perception of seediness, i.e., less seedy. For overall quality, ORUS 1380-1 was ranked very similar to 'Marion'.
One of the difficulties with this type of evaluation is that all knowledgeable evaluators are very familiar with what 'Marion' looks like. As a result, there may be an unconscious bias in favor of 'Marion' when evaluating IQF fruit. This potential bias is eliminated in the puree products.

Puree evaluation. Evaluating pureed products is advantageous as it removes the ability of the evaluator to identify the genotype by physical characteristics, eliminating any bias towards large or small fruit, and producing a more homogenous sample of fruit to the evaluators. There were significant differences among the genotypes for all traits except color for the pureed product (Fig. 2). For aroma and flavor, ORUS 1843-3 and ORUS 1843-1 were the top ranked genotypes. ORUS 1843-3, while ranked first, was only statistically different from the two lowest ranked genotypes for aroma and the four lowest ranked genotypes for flavor. ORUS 1489-2 was consistently ranked the poorest of all genotypes tested for aroma and flavor, while ORUS 1486-2 was also ranked very low. While there were no significant differences among the genotypes for their color rankings, there were two interesting samples. 'Chester Thornless' had an extremely dark color whereas 'Marion's color is normally more red than most other blackberries. 'Marion' scored the lowest of all genotypes for color. For overall quality, ORUS 1843-1 and ORUS 1843-3 were ranked the best but were not significantly different from ORUS 1380-1 and eight others. Only 1489-2 was ranked significantly lower. Most important was that 'Marion' was not rated significantly different from any other selection tested except ORUS 1489-2, which other than for color was universally the poorest pureed product.

Overall evaluation of genotypes. Based on in field evaluation and previous evaluations, there are a number of promising USDA-ARS selections in commercial grower trials and that are commercially available from nurseries as unnamed selections.

Currently, NZ 9128R-1 is being widely planted in the commercial industry. While NZ 9128R-1 was consistently rated similarly to 'Marion' for most IQF and puree traits, it scored lower than 'Marion' for IQF flavor and overall quality. ORUS 1380-1 scored either very close to or higher than 'Marion' for all attributes as an 
IQF and as a puree product and appears to be a very good replacement for 'Marion'.

When we began incorporating $R$. ursinus into our breeding material we felt that its flavor and low seediness were outstanding attributes. This panel largely confirmed that using this

Fig. 1. Mean scores for blackberry selections and cultivars evaluated by an untrained expert panel as individually quick-frozen product (IQF).
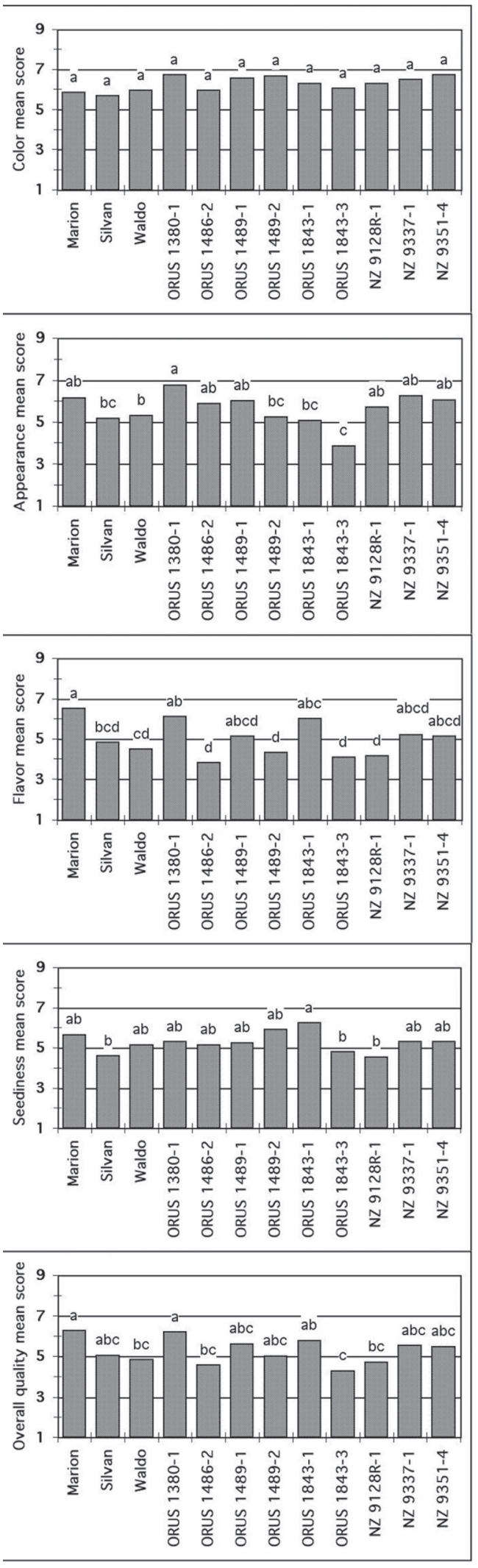

germplasm could improve our breeding germplasm and showed that it could perform well in a thornless genetic background. While ORUS 1843-3 generally scored poorly as an IQF product, probably due to a few poor samples, its sibling ORUS 1843-1 scored very well except for appearance. The appearance scores were poor as the fruit were much smaller than the other genotypes. ORUS 1843-1 and ORUS 1843-3 scored extremely well for all traits as a puree, and with the exception of the color scores were the top two genotypes. ORUS 1843-3 is being planted in significant commercial acreage.

'Silvan', 'Waldo', and 'Chester Thornless' were included in this evaluation as representatives of commercially available cultivars. 'Silvan', which is touted as a 'Marion' replacement was ranked lower (though not significantly) than 'Marion' for all traits as an IQF product. As a puree, it was rated slightly higher (though
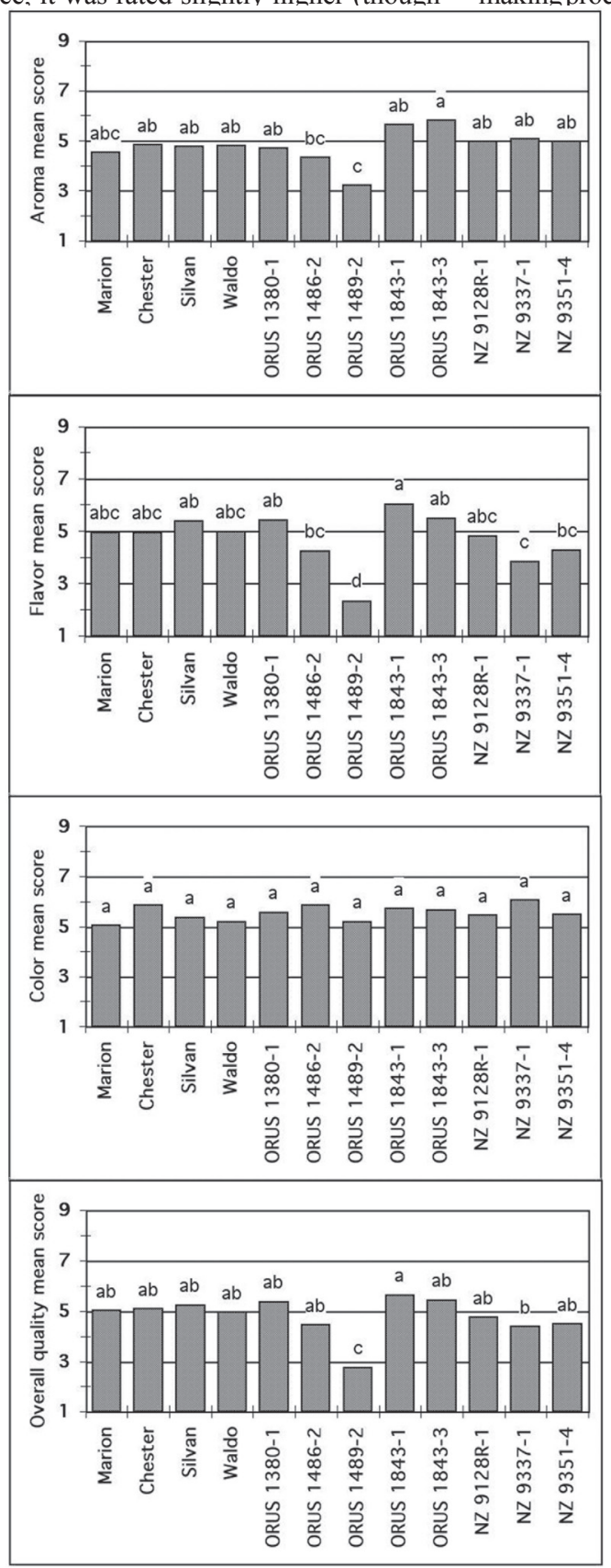

not significantly) than 'Marion' for all traits. 'Waldo', a trailing thornless cultivar, was ranked lower than 'Marion' for all IQF traits except for color, but as a puree was higher than 'Marion' except for overall quality where it was rated very similarly. 'Chester Thornless', a semi-erect blackberry, was not included in the IQF evaluation because every time we have included in trials before, its large, noticeable seeds, have pulled down its overall scores. As a puree, 'Chester Thornless' was rated better(though not significantly) than 'Marion' for any trait except flavor where it was rated identically. 'Chester Thornless' puree was a very dark purple, nearly black, color which for this panel was perceived as being more attractive than the lighter, more red hued, 'Marion' puree.

This evaluation successfully identified advanced selections that were similar to or better than 'Marion' as an IQF or pureed product. This information will be valuable in the final decision making process on which selections to release as cultivars and on which genotypes to plant commercially.

\section{Literature Cited}

Fan-Chiang, H.1999. Anthocyanin pigment, nonvolatile acid and sugar composition of blackberries. MS thesis. Ore. State Univ., Corvallis. Finn, C. 2001. Trailing blackberries: From clear-cuts to your table. HortScience 36:236-238.

Finn, C., K. Wennstrom, T. Mackey, R. Martin, B. Yorgey, B. Strik, G. Murray, and C. Pace. 2001. Thornless blackberries: In search of the holy grail, p 197-199. Proc. 2001 Ore. Hort. Soc. Mtg., Portland.

Finn, C., B.C. Strik, and F.J. Lawrence. 1997. Marion trailing blackberry. Fruit Var. J. 51:130-132.

Hall,H.K. 1990. Blackberry breeding. Plant Breed. Rev. 8:249-312.

Hall, H.K., R.M Skirvin, and W.F. Braam. 1986. Germplasm release of 'Lincoln Logan', a tissue culturederived genetic thornless 'Loganberry'. Fruit Var. J. 40:134-135.

Jennings, D.K. 1988. Raspberries and blackberries: Their breeding diseases and growth. Academic Press, New York.

Klesk, K. and M. Qian. 2003. Preliminary aroma comparison of Marion (Rubus spp. hyb) and Thornless Evergreen ( $R$. laciniatus L.) blackberries by dynamic headspace/OSME technique. J. Food Sci. 68:697-700.

Oregon Agricultural Statistical Service. 2002. 2001 Berry production down 6 percent. Ore. Agr. Stat. Serv., Portland.

Strik, B. and G. Buller. 2002. Reducing thorn contamination in machine-harvested 'Marion'blackberry. Acta Hort. 585:677-681.

Waldo, G.F. 1977. 'Thornless Evergreen' - Oregon's leading blackberry. Fruit Var. J. 31:26-30.

Fig. 2. Mean scores for blackberry selections and cultivars evaluated by an untrained expert panel as puree product. 